University of Warwick institutional repository: http://go.warwick.ac.uk/wrap This paper is made available online in accordance with publisher policies. Please scroll down to view the document itself. Please refer to the repository record for this item and our policy information available from the repository home page for further information.

To see the final version of this paper please visit the publisher's website. Access to the published version may require a subscription.

Author(s): Neil Marlow, Enid M. Hennessy, Melanie A. Bracewell and Dieter Wolke

Article Title: Motor and Executive Function at 6 Years of Age After

Extremely Preterm Birth

Year of publication: 2007

Link to published version: http://dx.doi.org/ 10.1542/peds.2007-0440

Publisher statement: None 


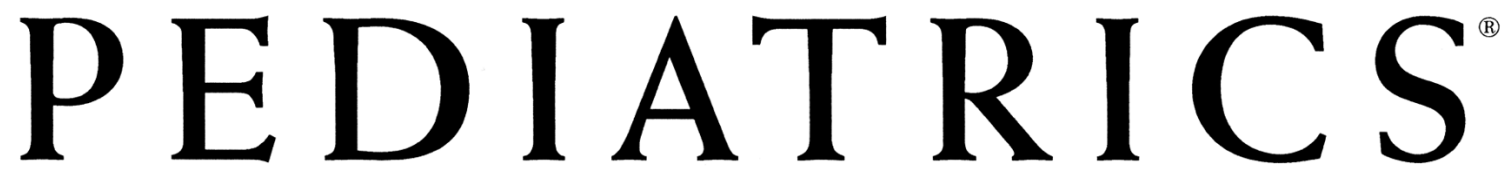

OFFICIAL JOURNAL OF THE AMERICAN ACADEMY OF PEDIATRICS

Motor and Executive Function at 6 Years of Age After Extremely Preterm Birth

Neil Marlow, Enid M. Hennessy, Melanie A. Bracewell, Dieter Wolke and for the EPICure Study Group

Pediatrics 2007;120;793-804

DOI: $10.1542 /$ peds.2007-0440

The online version of this article, along with updated information and services, is located on the World Wide Web at:

http://www.pediatrics.org/cgi/content/full/120/4/793

PEDIATRICS is the official journal of the American Academy of Pediatrics. A monthly publication, it has been published continuously since 1948. PEDIATRICS is owned, published, and trademarked by the American Academy of Pediatrics, 141 Northwest Point Boulevard, Elk Grove Village, Illinois, 60007. Copyright @ 2007 by the American Academy of Pediatrics. All rights reserved. Print ISSN: 0031-4005. Online ISSN: 1098-4275.

\section{American Academy of Pediatrics}

DEDICATED TO THE HEALTH OF ALL CHILDREN ${ }^{m}$ 


\title{
Motor and Executive Function at 6 Years of Age After Extremely Preterm Birth
}

\author{
Neil Marlow, DMa, Enid M. Hennessy, MSc ${ }^{\text {, }}$ Melanie A. Bracewell, MBBSa, Dieter Wolke, PhDc, for the EPICure Study Group \\ aSchool of Human Development, University of Nottingham, Nottingham, United Kingdom; bWolfson Institute, Queen Mary's School of Medicine and Dentistry, University \\ of London, London, United Kingdom; 'Department of Psychology and Warwick Medical School, University of Warwick, Warwick, United Kingdom \\ The authors have indicated they have no financial relationships relevant to this article to disclose.
}

\section{ABSTRACT}

BACKGROUND. Studies of very preterm infants have demonstrated impairments in multiple neurocognitive domains. We hypothesized that neuromotor and executive-function deficits may independently contribute to school failure.

METHODS. We studied children who were born at $\leq 25$ completed weeks' gestation in the United Kingdom and Ireland in 1995 at early school age. Children underwent standardized cognitive and neuromotor assessments, including the Kaufman Assessment Battery for Children and NEPSY, and a teacher-based assessment of academic achievement.

RESULTS. Of 308 surviving children, 241 (78\%) were assessed at a median age of 6 years 4 months. Compared with 160 term classmates, 180 extremely preterm children without cerebral palsy and attending mainstream school performed less well on 3 simple motor tasks: posting coins, heel walking, and 1-leg standing. They more frequently had non-right-hand preferences (28\% vs $10 \%)$ and more associated/overflow movements during motor tasks. Standardized scores for visuospatial and sensorimotor function performance differed from classmates by 1.6 and 1.1 SDs of the classmates' scores, respectively. These differences attenuated but remained significant after controlling for overall cognitive scores. Cognitive, visuospatial scores, and motor scores explained $54 \%$ of the variance in teachers' ratings of performance in the whole set; in the extremely preterm group, additional variance was explained by attention-executive tasks and gender.

CONCLUSIONS. Impairment of motor, visuospatial, and sensorimotor function, including planning, self-regulation, inhibition, and motor persistence, contributes excess morbidity over cognitive impairment in extremely preterm children and contributes independently to poor classroom performance at 6 years of age.

www.pediatrics.org/cgi/doi/10.1542/ peds. 2007-0440

doi:10.1542/peds.2007-0440

Key Words

infant, preterm, child development, neuropsychology, executive function, intelligence

Abbreviations

EP-extremely preterm ABC-Assessment Battery for Children K-ABC - Kaufman Assessment Battery for Children

$\mathrm{Cl}$ - confidence interval

Accepted for publication Apr 30, 2007

Address correspondence to Neil Marlow, DM, Academic Division of Child Health, Level E East Block, Queens Medical Centre, Nottingham NG7 2UH, United Kingdom. E-mail: neil. marlow@nottingham.ac.uk

PEDIATRICS (ISSN Numbers: Print, 0031-4005; Online, 1098-4275). Copyright $\odot 2007$ by the American Academy of Pediatrics 
$\mathrm{T}$ HERE IS MUCH public and professional concern over the long-term sequelae associated with survival at extremely low gestational ages $(<26$ weeks). We reported overall disability rates for a geographically defined cohort of such infants born in 1995 at 30 months of age ${ }^{1}$ and at 6 years. ${ }^{2}$ At the latter age, comparison of outcome was referenced to the performance of contemporary classmates. The most common disability was cognitive impairment and when the results of testing were categorized by the results of the contemporary peer comparison group, the rates of disability rose such that $46 \%$ were in the severe/moderate group (IQ scores less than -2 SD of the comparison group) and am additional $34 \%$ were mildly impaired (scores -1 SD to -2 SD of comparison group).

Motor impairments have long been recognized in preterm children without cerebral palsy. ${ }^{3}$ Much of the motor impairment relates to poor performance in relation to the low cognitive scores generally found in preterm children, ${ }^{4}$ but it has been suggested that motor and other neuropsychological problems may also occur independently of cognitive impairment in very low birth weight children. ${ }^{5}$ The contribution of primary motor problems to the totality of impairment in extremely preterm (EP) infants without cerebral palsy is unclear.

Executive functions are broadly synonymous with function of the prefrontal cortex of the brain and supporting loops ${ }^{6}$ but may be variously interpreted as functions needed to achieve goal directed behavior. Evaluation of such areas may, therefore, be useful in attempting to unravel the causes of poor motor function in preterm children.

In this article we report the results from a range of motor and executive tasks and evaluate the contribution of these areas to impairment at early school age for a cohort of EP children in mainstream education, to determine whether these problems provide additional morbidity for the EP child in daily life. We hypothesized that differences in motor and neuropsychological scores between preterm and comparison children would be independent of overall cognitive performance and lead to poorer school performance than explained by cognitive test score alone.

\section{METHODS}

\section{Study Subjects}

We identified all children born at $\leq 25$ weeks 6 days of gestation in the United Kingdom and Ireland from March through December 1995.7 Of the 308 children that were known to be alive at 30 months of age, all had survived to 6 years; 15 of these children were living outside the United Kingdom or Ireland. Of the remaining 293 children, 241 (78\% survivors) participated in this study at a median age of 76 months (range: 62-68 months); 34 were being educated at schools for children with special needs, 3 in a special needs class attached to a mainstream school, and 204 in a mainstream school class. Of these 204, 180 had no significant neurologic abnormality (cerebral palsy or hypotonia resulting in reduced mobility). One hundred sixty children acted as classmate comparisons as described previously, 2 were not included in this analysis because we were unable to obtain a full test profile as described here. ${ }^{2}$ All parents gave written informed consent, and the study was approved by the Trent Multicenter Research Ethics Committee and the local education authorities in Scotland.

\section{Assessment}

The children in mainstream school or attached units were evaluated by using clinical and neuropsychological assessments. Seven experienced developmental pediatricians and 8 psychologists performed the assessments, after reaching the required level of competence $(>80 \%$ agreement with independent observer for video-recorded tasks). The assessors were unaware of the neonatal courses of the children they evaluated and were not informed which children were preterm and which were controls.

Formal cognitive assessment for all children was made by the psychologist using the Kaufman Assessment Battery for Children (K-ABC). ${ }^{8}$ Only 4 children without cerebral palsy in mainstream school could not be assessed with the K-ABC. Four scales were reported: mental processing composite (general cognitive ability), simultaneous processing, sequential processing, and achievement scales. Furthermore, we obtained information about school achievement from each child's class teacher and derived a Teacher's Academic Achievement Scale. ${ }^{9}$

Motor function was assessed by the clinicians using 3 items from the Movement Assessment Battery for Children $(\mathrm{ABC})$ : time to post 12 coins; heel-toe walking (15 steps), and 1-leg balance (>20 seconds). ${ }^{10}$ Each item from the Movement $\mathrm{ABC}$ may also be scored from 0 to 5 in 1/2-point increments.

Additional information about motor/executive function was derived from the administration of items selected from 3 domains of the neuropsychological battery, NEPSY: sensorimotor, visuospatial and attention-executive. ${ }^{11}$ In this test standardized scores can be derived from core items, to which may be added supplemental items to derive additional information about performance in these domains. Overall core domain scores, individual item scaled scores or percentile rankings (presented in 5 groups) are reported as appropriate. We administered:

- Three visuospatial domain items: design copying, which assesses visuomotor integration by copying 2-dimensional figures on paper; arrows in which children are asked to judge line orientation and direction 
(scores of both are summed to produce a core domain score); and route finding, which evaluates understanding of visuospatial relationships and directionality.

- Four sensorimotor domain items: fingertip tapping, which assesses finger dexterity in simple and complex movements; imitating hand postures, in which the child has to reproduce a hand position made by the examiner without assistance from the contralateral hand; visuomotor precision where the child draws inside 3 consecutively narrower tracks without overwriting the outer lines (all 3 summed for the core domain score); and finger discrimination, which assesses the child's ability to perceive sensory stimuli without visual clues.

- Four attention-executive items: the "tower," which assesses planning, monitoring, self-regulation, and problem solving; visual attention, which assesses speed and accuracy in scanning an array of images and locating a target (these 2 scales form part of the core domain score); and we administered "statue," where inhibition and motor persistence are evaluated during a 75-second period standing with eyes, as a measure of ability to inhibit response to distracters; and "knock and tap," which evaluates self-regulation and ability to inhibit immediate impulses when presented with conflicting visual and verbal directions. The latter 2 scales were included as specific measures of attention, given that this is the most common area of executive problem reported in this group. The visual attention scale comprises 3 arrays, the third of which (matching 1 of 2 target faces) was abandoned because children found this too difficult and rapidly lost interest despite it being considered an age-appropriate task. Thus, in this domain, we only administered 2 of 3 core domain items (the third, auditory discrimination, was evaluated as part of a separate language assessment not reported here), and we calculated a composite measure, scaled to 100, which was used in the factor analysis.

Each child received a full neurologic assessment, ${ }^{2}$ including the 2 tests of neurologic performance described by Fog and Fog. ${ }^{12}$ The preferred hand was identified by asking the child to perform 7 actions on 2 occasions (picking up a block, using a spoon, placing a brick on a tower, using a pencil, using a crayon, pointing to a picture, and throwing a ball). These results were reduced to a score of right-handedness by dividing the number of times the right hand was preferred by 14. This score ranged from 0 (all performed with the left hand) to 1 (all with the right), and scores of 0.5 to 1 were classified as the preferred hand being the right, the remainder as nonright.

We classified children into 4 functional groups of disability as described previously. ${ }^{2}$ Cerebral palsy was classified independently of the degree of disability; this classification was made retrospectively at the completion of the study according to the description of functions for each limb ${ }^{13}$ by 2 assessors.

\section{Statistical Analysis}

Data collected on standardized forms were encoded for computer analysis with SPSS 11.0.0 for Windows (SPSS, Chicago, IL). The assessment data for each child were examined before the data were combined with the previous main study data set for analysis. Comparisons were made by using nonparametric statistics, where appropriate. Multiple regression was used to estimate independent effects. The iterated principal factor method was used to calculate the factors. Stata 9 (StataCorp, College Station, TX) was used for the final analyses.

\section{RESULTS}

EP children receiving separate special education and children who had signs of cerebral palsy were excluded from this analysis because we intended to study motor and executive function for children without overt neurologic problems in relation to their peers; these comprised 180 EP children and 158 comparison children who completed most of the tests. A few EP children for various reasons were unable to take individual tests; 4 children were unable to complete the K-ABC subtests but did complete some $(n=2)$ or all $(n=2)$ of the tests discussed in this article. The results for these children were entered as missing values in the relevant analyses; no substitutions were made. The gestational age, gender, plurality, and birth weight of the children included in this analysis are shown in Table 1.

\begin{tabular}{|c|c|c|c|}
\hline \multirow[t]{2}{*}{ TABLE 1} & \multicolumn{3}{|c|}{$\begin{array}{l}\text { Gestation, Gender, Plurality, and Cognitive Scores in } \\
\text { Extremely Preterm and Comparison Children Included in } \\
\text { the Study }\end{array}$} \\
\hline & & $\begin{array}{l}\text { Extremely } \\
\text { Preterm }\end{array}$ & Comparison \\
\hline N & & 180 & 158 \\
\hline \multicolumn{4}{|c|}{ Gestation, n (\%) } \\
\hline $25 w k$ & & $114(63)$ & - \\
\hline $24 w k$ & & $49(27)$ & - \\
\hline $23 w k$ & & $17(9)$ & - \\
\hline Boys, $n(\%)$ & & $81(45)$ & $71(44)$ \\
\hline \multirow{2}{*}{\multicolumn{2}{|c|}{$\begin{array}{l}\text { Multiple pregnancy, } n(\%) \\
\text { Age at assessment, median } \\
\quad \text { (interquartile range), y }\end{array}$}} & $51(28)$ & 0 \\
\hline & & $6.33(5.17-7.25)$ & $6.17(5.08-7.18)$ \\
\hline \multicolumn{2}{|c|}{$\begin{array}{l}\mathrm{K}-\mathrm{ABC} \text { MPC, median score } \\
\text { (interquartile range) }\end{array}$} & $90(78-99)$ & 105 (99-113) \\
\hline \multicolumn{2}{|c|}{ Simultaneous } & $89(79-97)$ & $104(95-111)$ \\
\hline \multicolumn{2}{|c|}{ Sequential } & $95(85-106)$ & $106(98-115)$ \\
\hline \multicolumn{2}{|c|}{ Achievement } & $84(68-93)$ & $102(92-109)$ \\
\hline
\end{tabular}

- indicates not applicable; MPC, mental processing composite. 


\section{Motor Tasks}

For each Movement ABC item, the median item score for the EP children was higher, denoting greater impairment, than for the comparison group (Table 2). The distribution of posting times in control children was skewed toward those who perform less well; that is, those with longer times. For the preferred hand, although the modal value (19 seconds) was the same in both groups, it was also the median value for comparison children, whereas only $25 \%$ of the EP children were faster than 19 seconds (Fig 1). There are highly significant differences between the medians for each measure, and highly significant differences between the variances (Table 2). The differences at the upper quartile (faster posting) are less than the difference between the lower quartile, and the differences are even more extreme at the 90th centile. Figure $2 \mathrm{~A}$ and B shows the nonnormality of the data for the 1-leg standing raw scores. In both groups, the modal value is 20 (maximum), but there is a very different distribution for the scores of EP children. The distributions of heel-toe walking raw scores show similar effects (Fig 2C). The medians and quartiles differ significantly as do the variances (Table 2). The less extreme $P$ value for the difference in variance for posting may be an arithmetic artifact because the data are more symmetrical in the EP children in contrast to the control children.

After adjustment for cognitive scores, the difference in means reduced to 1.7 seconds (95\% confidence interval $[\mathrm{CI}]: 0.6$ to 2.9$)$ for the preferred hand and 1.7 seconds (95\% CI: 0.1 to 3.4 ) for the nonpreferred hand. The difference in mean posting score remained significant (0.5 [95\% CI: 0.2 to 0.9]), whereas the means of the difference between the slowest and fastest hand did not.

\section{Neuropsychological Tests}

Items from 3 scales of the NEPSY battery were administered as described; core domain scores were more normally distributed than movement ABC task scores (Fig
3) as would be expected. Among EP children, visuospatial core domain scores (derived from design copying and arrows items) were, on average, 20.1 points (95\% CI: 17.3 to 22.9) lower than for those for the comparison children, equivalent to a reduction in SD score in the comparison group of 1.6 SD (Table 3). After adjustment for cognitive scores, this difference became 9.4 points (95\% CI: 6.7 to 12.1 ) or 0.76 SD $_{\text {comp lower. Median }}$ (quartile) scaled scores for the EP group were significantly lower than those of the comparison group (Table 4).

Sensorimotor core domain scores were reduced in the EP group by 15.5 points (95\% CI: 12.2 to 18.8 ) or 1.1 $\mathrm{SD}_{\text {comp, }}$ and this difference remained significant after adjustment for overall cognitive score $(7.2$ points [95\% CI: 12.2 to 18.8 ] or $\left.0.5 \mathrm{SD}_{\text {comp }}\right)$. Small but significant differences were noted in the sequential fingertip tapping task and in imitating hand postures with lower scaled scores for EP children (Table 4).

Scaled scores for the 2 core visual attention items (tower and visual attention) were lower in EP children than controls (Table 4; $P<.001$ ). Within the visual attention item, EP children took longer over the 2 tasks ("bunnies": 9 seconds [95\% CI of difference: 1.5 to 16.5] "kittens": 8 seconds [1.5-14.5]), made similar number of commission errors (incorrect responses: $P=.73$ and .18 , respectively $\left.\left[\chi_{\text {trend }}^{2}\right]\right)$ but more omission errors $(P=.008$ and $P<.001$, respectively) and demonstrated more off-task behavior $(P=.001$; Appendix 1). In a similar fashion on the visuomotor precision task (sensorimotor domain), and despite taking similar times to complete each of the 3 increasingly narrow pencil trails, EP children consistently made more errors (crossed the trail lines) than comparison children $(P=.002 ; P<.001 ; P<$ .001 , respectively; see Appendix 2).

The percentile rank scores for the 5 supplemental items are shown in Appendix 3. On each task, the rankings of the EP group denote more impaired performance

TABLE 2 Performance on the Movement-ABC-derived Tasks With Standardized Scores for Both Study Groups and for EP Boys and Girls

\begin{tabular}{|c|c|c|c|c|c|c|c|c|}
\hline \multirow[t]{2}{*}{ No. Included } & \multirow{2}{*}{$\begin{array}{l}\text { Extremely Preterm } \\
\qquad(N=180)\end{array}$} & \multirow{2}{*}{$\begin{array}{c}\text { Comparison } \\
(N=158)\end{array}$} & \multicolumn{2}{|c|}{$P$} & \multirow[t]{2}{*}{ EP Boys } & \multirow[t]{2}{*}{ EP Girls } & \multicolumn{2}{|c|}{$P$} \\
\hline & & & Median $^{a}$ & Variance $^{\mathrm{b}}$ & & & Mediana & Variance $^{\mathrm{b}}$ \\
\hline \multicolumn{9}{|l|}{ Posting 12 coins, $\mathrm{s}$} \\
\hline With preferred hand & $22(19-25)$ & $19.5(18-22)$ & $<.0001$ & $<.0001$ & $23(20-27)$ & $21(19-24)$ & .006 & .013 \\
\hline With nonpreferred hand & $24(21-30)$ & $22(19-25)$ & $<.0001$ & $<.0001$ & $25(23-32)$ & $24(21-29)$ & .014 & .4 \\
\hline Difference (slowest to fastest) & $3(2-8)$ & $3(1-5)$ & .0011 & .0001 & $3(2-8)$ & $3(2-6)$ & .8 & .04 \\
\hline Score $(0-5)$ & $2.5(1.5-4.0)$ & $1.0(0.0-2.0)$ & $<.0001$ & .03 & $2.75(2.0-4.5)$ & $2.5(1.0-3.5)$ & .021 & .7 \\
\hline \multicolumn{9}{|l|}{ Movement-ABC, $s$} \\
\hline Heel-toe walking (15 steps) & $13(8-15)$ & $15(15-15)$ & $<.0001$ & & $12(6-15)$ & $15(9-15)$ & .011 & \\
\hline Score $(0-5)$ & $1.0(0.0-4.0)$ & $0.0(0.0-0.0)$ & $<.0001$ & $<.001$ & $2.5(0.0-4.75)$ & $0.0(0.0-3.0)$ & .029 & .7 \\
\hline Right leg balance (20 s) & $7(4-17)$ & $18(9-20)$ & $<.0001$ & & $6(4-12)$ & $9(5-20)$ & .014 & \\
\hline Left leg balance (20s) & $8(5-16)$ & $17(8-20)$ & $<.0001$ & & $6(3-13)$ & $12(6-20)$ & .001 & \\
\hline Score $(0-5)$ & $2(0.5-4.0)$ & $0(0.0-1.5)$ & $<.0001$ & $<.001$ & $3.0(1.0-4.0)$ & $1.5(0.5-3.0)$ & .001 & 6 \\
\hline
\end{tabular}

Values are presented as median (interquartile range).

a Mann-Whitney $U$ test with adjustment for ties.

b Bartlett's test for equal variances. 
FIGURE 1

Individual scores on the posting task for preferred and nonpreferred hand for the EP and comparison children. The solid black line represents the median, and the dashed black represents line the 90 th percentile.

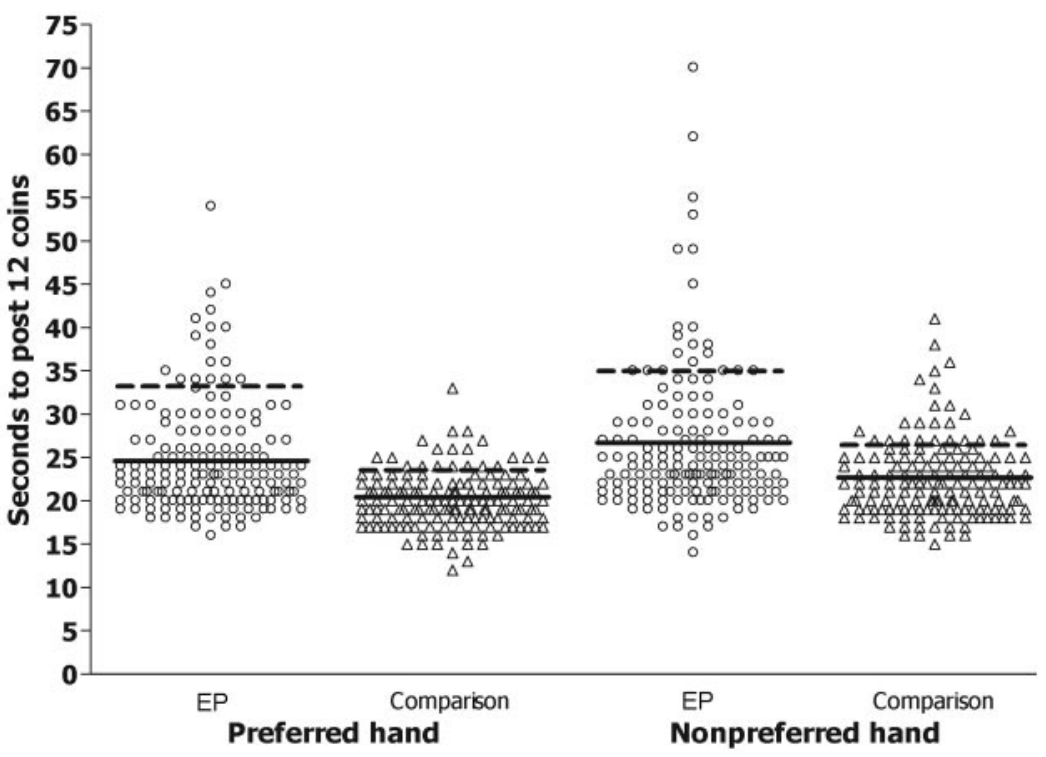

than comparison children $(P<.001$ for each comparison).

\section{Hand Preferences}

The distribution of hand preferences among the EP children was significantly more nonright than in the comparison children (Fig 4; Mann-Whitney $U$ test; $P<$ $.001)$. Ten percent of the comparison group showed nonright preference compared with $28 \%$ of the EP children, but there were no differences in the distribution of preferences for boys or girls within each group. The hand-preference score was linearly related to cognitive development in the EP group $(r=.17 ; P=.02)$; the stronger the right preference, the better the score, equivalent to 6 points (95\% CI: 0.8 to 11 ) over the whole scale. In contrast, the effect in the comparison children was not significant. Different effects were seen when visuospatial and sensorimotor core domain scores were evaluated. For the children in the EP group, there was no relation, but for comparison children visuospatial scores were positively related to hand-preference scores $(\mathrm{r}=.22 ; P=.007$; equivalent to 11 points [95\% CI: 3.2 to 20]). To investigate the effect of having a more complete preference for either the left or the right hand, the fully left- or right-handed were given a score of 1 , whereas those who had equal preferences for left and right were given a score of 0 , and the remainder proportionally in between. Only sensorimotor scores in the comparison children were affected by this so that the fully right- or left-handed had a mean 12-point advantage $(95 \%$ CI: -0.2 to $24 ; P=.053)$ compared with those who chose the left and the right hand equally.

\section{Neurologic Observations}

During the NEPSY items, EP children more frequently used immature $(4 \%)$ or intermediate $(50 \%)$ pencil grip than comparison children $(4 \%$ and $29 \%$, respectively; $P<.002$ $\left.\left[\chi_{\text {trend }}^{2}\right]\right)$. EP children were more likely to be unable to inhibit overflow movements during manual items. For example, associated movements during bimanual motor sequences were more prevalent in the EP group (123 children $[69 \%]$ ) compared with comparison (72 children [45\%]; $P<.001)$, and mirror movements were observed more frequently during fingertip tapping ( $46 \%$ v $32 \% ; P=$ $.01)$; in contrast, similar proportions of EP and comparison children used the contralateral hand as an aid during the imitating hand postures $(72 \%$ vs $62 \% ; P=.5)$.

On neurologic assessment, spontaneous abnormal movements were rarely seen (EP: 2 children; comparison: no children). In the Romberg position, $91 \%$ of the comparison children still had no involuntary movements, and $9 \%$ had distal movements with eyes closed. In contrast, $32 \%$ of the EP children showed involuntary movements, $11(6 \%)$ with eyes open and 45 children $(26 \%)$ during eye closure $\left(P<.001 ; \chi_{\text {trend }}^{2}\right)$. We specifically sought overflow movements using the 2 tests of Fog and Fog. ${ }^{12}$ On lateral foot standing, only $50 \%$ of EP children (87 of 173) had no involuntary dystonic movements compared with $77 \%$ (119 of 155) of comparison children. For 13 EP children, lateral foot standing caused postural loss ( 12 with internal and 1 with external arm rotation) compared with 2 comparison children (1\%). The differences in distribution of these signs was significant $\left(P<.001 ; \chi_{\text {trend }}^{2}\right)$. On the manual task (compression of a sprung paper clip), flexor or extensor mirror movements were found more commonly whether compression was with the right $(P<.001)$ or left hand $(P=$ $.04)$, respectively.

\section{Gender Differences}

Among the comparison children boys performed less well than girls on 1-leg standing (right leg: $P=.006$; left 
FIGURE 2

Distribution of raw scores on 3 gross motor tasks (1-leg standing for 20 seconds on the right $[A]$ and left $[B]$ legs and heel-toe walking for 15 steps [C]) for the EP and comparison children.
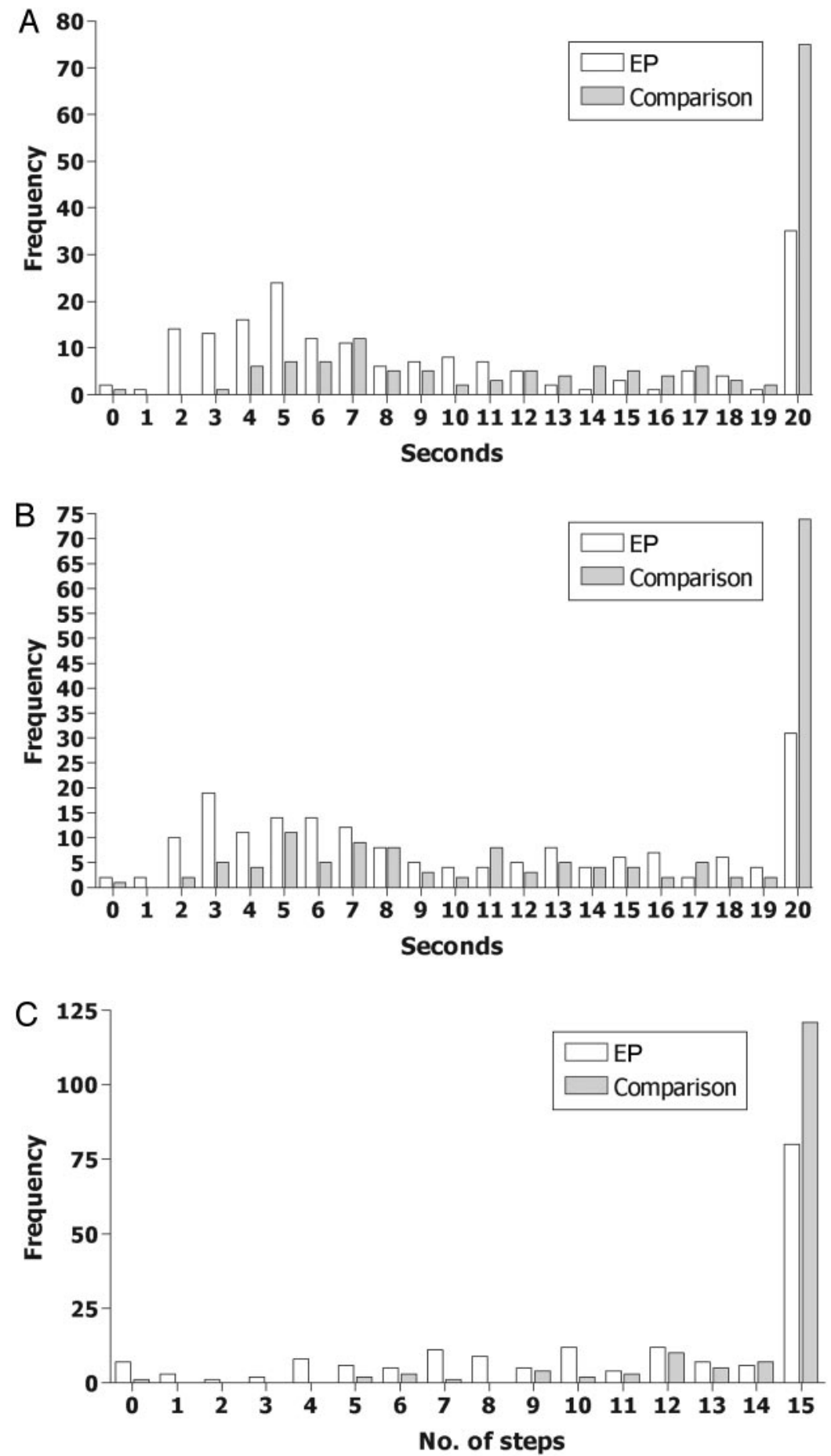

leg: $P=.60$ ), but in other areas there were no significant differences (sensorimotor: mean difference: $2.6[P=$ .26], visuospatial: $0.5[P=.82]$ ). In contras, EP boys performed significantly worse on all measures except the visuospatial score where scores were 3.2 points $(-0.7$ to 7.0) below those of girls. In the posting task, the boy-girl difference between preferred and nonpreferred hands was also 0 (Tables 2 and 3).

\section{Interrelationships Between Functions}

In the comparison group, visuospatial and sensorimotor scores were highly associated with overall cognitive function $(r=0.53$ and 0.33 , respectively; both $P<$ $.001)$. The association was higher in the EP group for both $(r=0.70$ and 0.49 , respectively; both $P<.001)$. For the comparison group, there were no gender differences in cognitive scores; in contrast, EP boys had sig- 
FIGURE 3

Individual scores on 3 sensorimotor, visuospatial, and attentionexecutive scales (NEPSY) for the EP and comparison children. The solid lines denote mean scores.

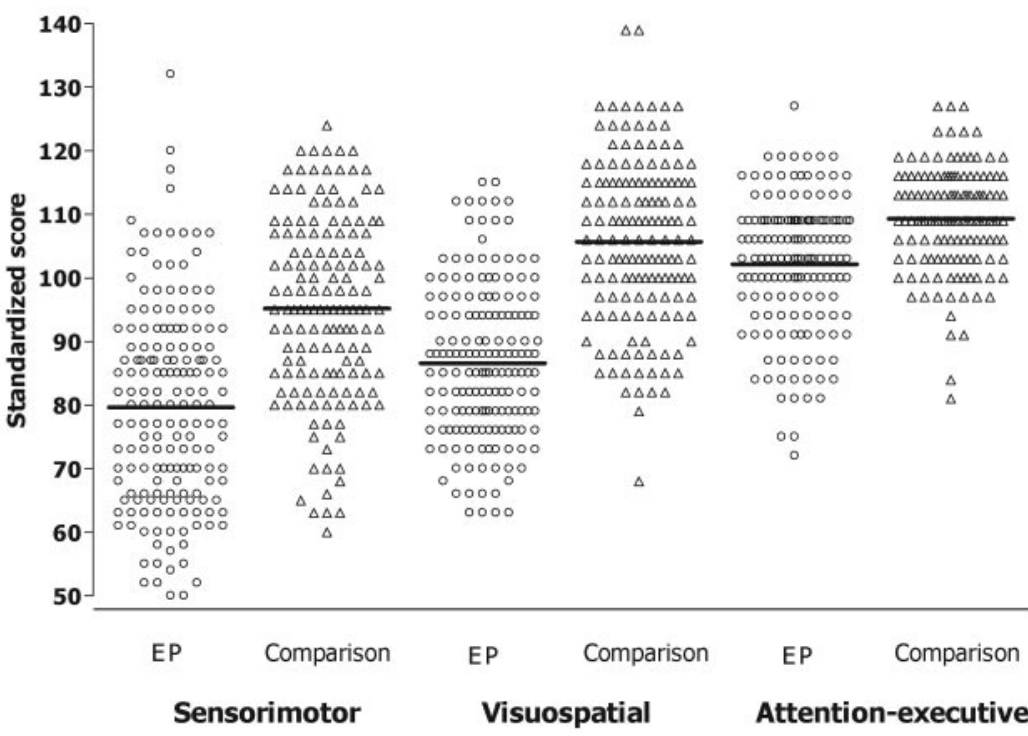

Sensorimotor
Visuospatial

\begin{tabular}{|c|c|c|c|c|}
\hline \multirow[t]{2}{*}{ TABLE 3} & \multicolumn{4}{|c|}{$\begin{array}{l}\text { Mean ( } 95 \% \mathrm{Cl} \text { of Mean) Standardized Scores for } 2 \text { NEPSY Core Domain Scores and Restricted } \\
\text { Attention-Executive Score According to Study Group and Child's Gender }\end{array}$} \\
\hline & & Visuospatial & Sensorimotor & Attention-Executive \\
\hline \multicolumn{5}{|c|}{ Extremely preterm versus comparison } \\
\hline EP & & 86.4 (84.5 to 88.4) & 79.7 (77.3 to 82.0) & 102.1 (100.5 to 103.7$)$ \\
\hline Compari & son & 106.5 (104.5 to 108.5$)$ & 95.2 (92.8 to 97.5$)$ & $109.3(108.0$ to 110.6$)$ \\
\hline Differenc & ce in means comparison - EP & 20.1 (17.3 to 22.9$)$ & 15.5 (12.2 to 18.8$)$ & $7.1(5.1$ to 9.3$)$ \\
\hline p & & $<.0001$ & $<.0001$ & $<.0001$ \\
\hline Adjusted & deficit in EP children ${ }^{a}$ & $9.4(6.7$ to 12.1$)$ & $7.2(3.5$ to 10.8$)$ & $3.2(0.8$ to 5.5$)$ \\
\hline IP & & $<.001$ & $<.001$ & .01 \\
\hline \multicolumn{5}{|c|}{ Boys versus girls } \\
\hline EP boys & & 84.7 (82.0 to 87.5) & 75.7 (72.4 to 78.9$)$ & 99.1 (96.9 to 101.3) \\
\hline EP girls & & 87.9 (85.2 to 90.6$)$ & $83.0(79.7$ to 86.3$)$ & 104.6 (102.4 to 106.8$)$ \\
\hline Difference & n means (girls - boys) EP group & $3.2(-0.7$ to 7.0$)$ & $7.3(2.6$ to 12.0$)$ & $5.5(2.4$ to 8.6$)$ \\
\hline$P$ value for & difference in EP & .10 & .002 & .0006 \\
\hline Difference & n means (girls - boys) control group & $0.5(-3.6$ to 4.5$)$ & $2.6(-2.0$ to 7.3$)$ & $2.3(-0.4$ to 5.0$)$ \\
\hline$P$ value for & difference in controls & .82 & .26 & .095 \\
\hline $\begin{array}{r}\text { Adjusted di } \\
\text { versu }\end{array}$ & \multicolumn{3}{|c|}{ versus comparison group ${ }^{b}$} & $3.5(1.5$ to 5.5$)$ \\
\hline$P$ & & .65 & .011 & .001 \\
\hline
\end{tabular}

nificantly lower mean cognitive scores than EP girls, in keeping with the findings for the whole cohort. ${ }^{2}$ The effect of the child's gender on NEPSY scores in the EP group becomes weaker after adjusting for cognitive scores, reducing the differences by approximately a half (Table 3). Of the significant predictors of NEPSY scores in regression, the models with the best fit had independent effects of cognitive score, male gender and being EP (Table 3). The best statistical model for these 2 scores was described by independent effects of cognitive score and male gender (either control or EP child) rather than an effect only of gender seen only in the EP children.

The sample size is too small after the exclusion of children receiving special education to detect an effect of gestational age over the range of gestations in the EP children as most were born at 25 weeks' gestation, and only 14 of those in this analysis were born at 23 weeks' gestation or earlier. There were no significant effects of gestation either in univariate analysis or after adjustment for cognitive scores.

Children were rated by teachers on a range of performance items to derive a total teachers' academic achievement score, ${ }^{9}$ which provided a composite functional measure of the child's performance in the classroom and ranged from 1 to 5. In univariate analyses, overall cognitive function and visuospatial scores were equally good predictors of total academic achievement score, accounting for $45 \%$ and $44 \%$ of the variance respectively. Combined heel and leg items accounted for $33 \%$ of the variance and sensorimotor scores $27 \%$. In 


\begin{tabular}{|c|c|c|c|c|}
\hline \multirow[t]{3}{*}{ TABLE 4} & \multicolumn{4}{|c|}{$\begin{array}{l}\text { Median (Quartile) NEPSY Item Scaled Scores in the } 3 \\
\text { Tested Domains Tested for Extremely Preterm and } \\
\text { Comparison Groups }\end{array}$} \\
\hline & & \multicolumn{2}{|c|}{ Median (Interquartile Range) } & \multirow[t]{2}{*}{$P$} \\
\hline & & $\begin{array}{c}\text { Extremely } \\
\text { Preterm }\end{array}$ & Comparison & \\
\hline \multicolumn{5}{|c|}{ Visuospatial } \\
\hline \multicolumn{2}{|c|}{ Design copying } & $8(7-10)$ & $12(10-14)$ & $<.001$ \\
\hline \multicolumn{2}{|c|}{ Arrows } & $7(6-8)$ & $10(8-11)$ & $<.001$ \\
\hline \multicolumn{5}{|c|}{ Sensorimotor } \\
\hline \multirow{2}{*}{\multicolumn{2}{|c|}{$\begin{array}{l}\text { Fingertip tapping } \\
\text { Imitating hand postures }\end{array}$}} & $9(4-11)$ & $11(8-12)$ & $<.001$ \\
\hline & & $7(5-9)$ & $9(8-11)$ & $<.001$ \\
\hline \multicolumn{2}{|c|}{ Visuomotor precision } & $6(5-8)$ & $9(7-11)$ & $<.001$ \\
\hline \multicolumn{5}{|c|}{ Attention-executive } \\
\hline \multicolumn{2}{|c|}{ Visual attention } & $8(7-9)$ & $9(8-10)$ & $<.001$ \\
\hline \multicolumn{2}{|c|}{ Tower } & $7(6-10)$ & $10(7-12)$ & $<.001$ \\
\hline \multicolumn{2}{|l|}{ Statue } & $10(7-11)$ & $11(9-11)$ & $<.001$ \\
\hline
\end{tabular}

multivariate analyses, cognitive function and visuospatial scores together accounted for $50 \%$ of the variance, whereas the addition of the motor items only accounted for a additional $2.6 \%$. Note that some values were missing for visuospatial scores (18 EP and 9 comparison) and total academic achievement score (29 EP and 13 comparison). Investigation showed only small differences in the cognitive scores and motor scores between those with and without data.

Using stepwise linear regression to determine the relative importance of the motor performance measures and cognitive performance in determining classroom function, 4 variables were found to explain $53 \%$ of the variance in teachers' scores. The independent regression coefficients for an increase of 1 SD (calculated from the comparison group) in the predictor variables: overall cognitive function: 0.19 (95\% CI: 0.11 to $0.27 ; P<$ .001 ), visuospatial score: 0.16 (95\% CI: 0.08 to $0.24 ; P<$ .001 ), heel walking item score: -0.07 (95\% CI: -0.13 to $-0.02 ; P=.01)$, and 1 -leg standing item score -0.08 (95\% CI: -0.15 to $-0.02 ; P=.01$ ). Note that higher scores in the last 2 variables denote worse performance. Adding EP status into the model explained a additional $1.2 \%$ of the variance (regression coefficient: -0.22 [95\% CI: -0.38 to $-.06 ; P=.01]$ ), whereas reducing only slightly the magnitude of the other coefficients. Being male was marginally significant in the EP group but not in the comparison group.

The $24 \mathrm{EP}$ children with cerebral palsy in mainstream school had worse outcomes than the other EP children for all measures considered here (Table 5) although the differences for cognitive score, visuospatial, attentionexecutive, and total academic achievement scores were only marginally different from other EP children after adjustment for their cognitive or sensorimotor scores.

In a factor analysis of the cognitive and NEPSY scores, both EP and comparison groups were substantially de- scribed by 2 factors, of which the first was the most dominant. Restricting the analysis to 2 factors the first had positive values for cognitive, visuospatial and sensorimotor scores. In the EP children there was also a large positive contribution from the restricted attentionexecutive score, which was not observed in the comparison children. The second factor had positive contributions from attention-executive (but in the EP group smaller than in the first factor) and sensorimotor scores, and smaller and differing contributions from the other 2 variables (Table 6).

\section{DISCUSSION}

Compared with classmates, we have demonstrated that EP children without cerebral palsy have high prevalences of impairment in visuospatial, perceptuomotor, attention-executive, and gross motor function at early school age. These deficits are greater than would be expected given the cognitive deficit we reported in this population. ${ }^{2}$ In each area, approximately half the deficit in motor skills or executive function was not accounted for by impairment in the cognitive score. It is likely, therefore, that motor and executive-function difficulties make an important additional contribution to the child's performance reported by teachers in the class setting.

The presence of motor difficulties in very low birth weight and preterm infants is well described. ${ }^{3}$ But even after excluding those with a diagnosis of cerebral palsy or those in a special school who will have poorer motor function than those analyzed, the deficit covers all areas tested and usually amounts to $>1$ SD of standardized tests. It is thus likely to be clinically important. ${ }^{14}$ Given the broad areas of difference between the EP children and their classmates over the range of functions examined it would seem that the summative epithet "poor motor skills" is likely to have a range of underlying etiologic pathways.

The core domain score for visuospatial performance was commonly the strongest independent variable in multivariate analysis. This domain comprises tests of visuomotor orientation, judgment, directionality and integration, which are key areas of performance in overall motor skills. Several studies have used the Beery test of Visuomotor Integration, which bears close similarities to the design-copying task in NEPSY. Those studies have identified deficits in visuomotor integration in populations of more mature very low birth weight infants. The deficit in visuospatial performance has implications beyond pencil skills and design concepts, because it indicates poor spatial judgment, poor concepts of orientation and directionality ${ }^{11}$ in significant numbers of EP children denoting important perceptual deficits. Additional impairment may arise from the deficits in manual dexterity, precision and sensory discrimination that are seen the sensorimotor domain.

The qualitative observations made alongside the test 
FIGURE 4

Distribution of hand-preference scores for the EP and comparison children over 14 tasks. Scores range from 0 (all left-handed) to 1 (all right-handed)

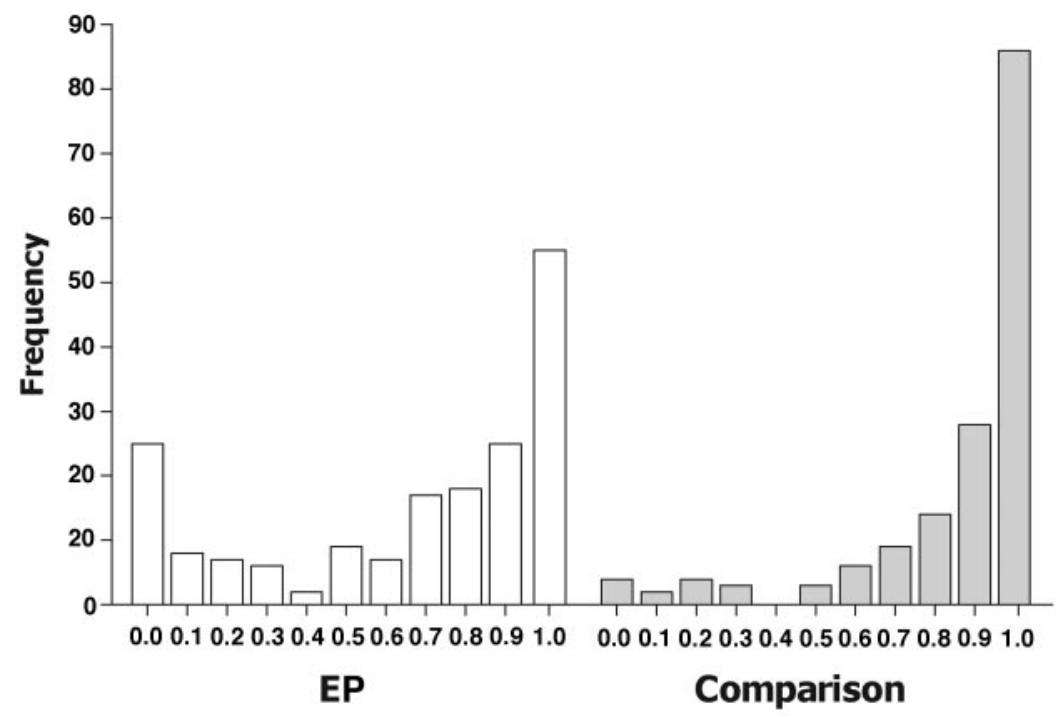

TABLE 5 Effect of Cerebral Palsy in EP Children in Mainstream School

\begin{tabular}{llcc}
\hline & Unadjusted & $\begin{array}{c}\text { Adjusted for Cognitive } \\
\text { Score }\end{array}$ & $\begin{array}{c}\text { Adjusted for Sensorimotor } \\
\text { Score }\end{array}$ \\
\hline Sensorimotor score & $8.2(1.1$ to 15.4$)$ & $6.8(0.4$ to 13.1$)$ & NA \\
Visuospatial score & $3.4(-2.4$ to 9.2$)$ & $-0.1(-4.0$ to 4.3$)$ & $-1.3(-6.5$ to 3.9$)$ \\
Attention-executive score & $2.1(-2.8$ to 7.1$)$ & $1.1(-3.4$ to 5.5$)$ & $-0.7(-5.1$ to 3.7$)$ \\
Total academic achievement score & $0.2(-0.1$ to 0.6$)$ & $-0.2(-0.3$ to 0.3$)$ & $-0.1(-0.39$ to 0.29$)$ \\
Cognitive score & $7(1.3$ to 12.6$)$ & $\mathrm{NA}$ & $-0.6(-5.8$ to 4.5$)$ \\
\hline
\end{tabular}

Mean difference in scores $(95 \% \mathrm{Cl})$ between those without cerebral palsy and those with cerebral palsy. NA indicates not applicable.

TABLE 6 Results of Factor Analysis (Unrotated): Factor Loadings

\begin{tabular}{|c|c|c|c|c|}
\hline & \multicolumn{2}{|c|}{ EP Group } & \multicolumn{2}{|c|}{ Comparison Group } \\
\hline & $\begin{array}{c}\text { Factor } \\
1\end{array}$ & $\begin{array}{c}\text { Factor } \\
2\end{array}$ & $\begin{array}{c}\text { Factor } \\
1\end{array}$ & $\begin{array}{c}\text { Factor } \\
2\end{array}$ \\
\hline Mental processing coefficient & 0.78 & -0.15 & 0.64 & 0.01 \\
\hline Restricted attention-executive score & 0.69 & 0.42 & 0.20 & 0.51 \\
\hline Sensorimotor score & 0.71 & 0.19 & 0.52 & 0.19 \\
\hline Visuospatial score & 0.85 & -0.37 & 0.86 & -0.24 \\
\hline Combined variance explained by factor, $\%$ & 86 & 14 & 80 & 20 \\
\hline
\end{tabular}

items indicate that EP children spend longer time periods on tasks and have greater difficulty inhibiting associated movements and providing secure postural basis for activities. We have demonstrated this by observation during the test administration and by formal standardized examination. ${ }^{12}$ We were surprised that as many as $7 \%$ EP children lost postural control, for example on lateral foot standing (compared with $1 \%$ of comparison children). However, it should also be noted that significant numbers of comparison children exhibited off-task behavior ( $17 \%$ vs $25 \%$ ), mirror movements ( $32 \%$ vs $46 \%$ ) and overflow movements ( $45 \%$ vs $69 \%$ ), such that although the quantum of abnormal neurology was higher among the EP children, its presence was not specific to that group. The below standard test norm performance in the sensorimotor tasks by the comparison children may indicate a general shift to poorer sensorimotor coordination in children noted by others. ${ }^{15}$ "Soft" neurologic signs were more frequently in children who were of very low birth weight, ${ }^{16}$ and we have shown previously that there is a strong relationship between these signs at 6 years and performance on the Test of Motor Impairment, the predecessor to the Movement ABC. ${ }^{17}$

In this analysis, EP boys fared worse than girls, which is a recurring theme in this population where boys have higher mortality and neonatal morbidity, ${ }^{7}$ perform less well over the first 30 months $^{1}$ and have more disability and poorer cognitive scores at this assessment than girls. ${ }^{2}$ Much of the gender difference in motor and executive scores could be explained by the boys' poorer overall cognitive scores, but there remained a statistically significant effect after adjustment, both overall and when 
restricted to the EP group. These data are more consistent with a real worsening of these scores in EP boys at school. Where there is a difference in sensorimotor scores between the genders, after adjustment for overall cognitive scores, our data are equally consistent with either a general worsening of scores in boys or with the detrimental effect of extreme prematurity being particularly prevalent in boys.

In a factor analysis of very low birth weight infants in Northern Germany who had comprehensive assessments, 2 principal components were found, both positively associated with cognitive function/language and motor performance; ${ }^{5}$ the first and strongest component was more strongly associated with the cognitive/language function and the second with motor performance, and in children with no apparent problems the second factor was barely associated with cognitive/language function.

The tests and scales in our data are different, but we looked to see whether there were similar factors, separately for the EP and control children. For the comparison children, the results were consistent in this and the German data. The primary factor was similar in both of our study groups, in that it was strongly associated with motor tests, visuospatial scores, and cognitive function, whereas the secondary factor were related somewhat to motor function and visuospatial function but not cognitive function. The secondary factors in the comparison children were not easy to interpret, and did not seem to be related to motor function. Interestingly, in both the German children and in our comparison children, a measure of concentration (Frankfurt test of concentration or attention-executive score, respectively) had a much reduced association with the primary factor, whereas it was more strongly associated with the primary factor in with the EP children in this study and in an intermediate fashion for the German children with cerebral palsy. This is because attention-executive scores in this study are positively associated with the other measures in the EP children but not the controls. It could be suggested that in normal children of 6 years development of visuospatial, motor and cognitive skills are highly correlated and relatively independent of their ability to concentrate, whereas in EP children either the ability to concentrate is damaged at the same time as their cognitive and motor skills, or in these vulnerable children poorer attention-executive scores makes it less likely that they will achieve higher scores for these outcomes.

Laterality of hand function in this population is affected by EP birth. The proportion of children with nonright lateralization is high in the preterm group. The excess of nonright lateralization is comparable to previous findings in very low birth weight children, ${ }^{18-22}$ and may represent poor neurologic organization as a result of poor postnatal brain growth found in this ${ }^{23}$ and in other populations..$^{24,25}$
The degree of nonright lateralization is associated with cognitive and visuospatial performance in the EP children, but less so in the comparison children. There is less evidence to suggest that it is associated with motor performance in either group, and no evidence that it is associated with attention-executive scores. Effects shown in previous studies have been inconsistent. ${ }^{18,20,22}$ In this study we have excluded those with neurologic problems, who have an even higher prevalence of non-right-hand preference ${ }^{20}$ and, therefore, a closer relationship to poor cognitive or motor performance.

The overwhelming impression is one of children with a global reduction in ability both in terms of general cognitive performance and specific motor or executive tasks, whether perception, processing or execution of tasks are considered. This conclusion supports that of Anderson and colleagues who examined a geographically based cohort of very preterm or extremely low birth weight children at 8 to 9 years with a similar breadth of tests ${ }^{26}$ and more recently those of Bohm et al, ${ }^{27}$ who evaluated NEPSY results in very low birth weight children at 5 years. Similar findings were observed in a more heterogeneous group of very low birth weight children at $51 / 2$ years in the children who had been smallest at birth. ${ }^{28}$ Other studies have demonstrated, for example, spatial working memory deficits, ${ }^{29}$ and planning, sequencing and inhibition impairments ${ }^{30}$ at around 4 years of age in small groups of preterm populations as part of focused assessment which fail to demonstrate the more global impairment identified here.

\section{CONCLUSIONS}

Our study confirms that impairments in both simple motor skills and more complex visuospatial and perceptuomotor ability are highly prevalent in his large study of EP infants. These impairments contribute additional morbidity to the cognitive morbidity that we have described previously. ${ }^{31}$ The tests of attention-executive function described in these children evaluate the areas of planning, self-regulation, visual search accuracy, inhibition, and motor persistence. In parallel to the visuospatial and sensorimotor difficulties described, impairments in these areas also contribute to the totality of morbidity. Future analysis will have to determine whether specific learning difficulties such as in language or behavioral and social difficulties ${ }^{32}$ are important additional predictors of school achievement. Although these motor difficulties provide only a relatively small extra contribution to total school achievement, they provide an area of performance that may be amenable to successful intervention or therapy.

\section{ACKNOWLEDGMENTS}

This work was supported by grants from BLISS, the Health Foundation, and WellBeing to Drs Marlow and Wolke. 
The EPICure Study Group was responsible for steering the project from its inception: K. Costeloe (London), A. T. Gibson (Sheffield), E. M. Hennessy (London), N. Marlow (Nottingham), A. R. Wilkinson (Oxford), and D. Wolke (Warwick); and the developmental panel was responsible for data collection and entry. The pediatricians were Melanie Bracewell, Michele Cruwys, Ruth MacGregor, Lesley McDonald, Margaret Morton, Margaret Morris, and Sue Thomas, and the psychologists were Emma Luck, Catherine Bamford, Helen Betteridge, Hanne Bruhn, Sandra Johnson, Iliana Magiati, Maria Morahan, and Isabel Tsverik. Muthanna Samara assisted with the psychological data analysis, and Heather Palmer was the study administrator.

We thank the children, parents, and schoolteachers who made this study possible, and we acknowledge the invaluable help of the pediatricians in 276 maternity units across the United Kingdom and Ireland who contributed data to the original study.

\section{REFERENCES}

1. Wood NS, Marlow N, Costeloe K, Gibson AT, Wilkinson AR. Neurologic and developmental disability after extremely preterm birth. EPICure Study Group. $N$ Engl J Med. 2000;343: 378-84

2. Marlow N, Wolke D, Bracewell MA, Samara M. Neurologic and developmental disability at six years of age after extremely preterm birth. $N$ Engl J Med. 2005;352:9-19

3. Bracewell M, Marlow N. Patterns of motor disability in very preterm children. Ment Retard Dev Disabil Res Rev. 2002;8: 241-248

4. Bhutta AT, Cleves MA, Casey PH, Cradock MM, Anand KJ. Cognitive and behavioral outcomes of school-aged children who were born preterm: a meta-analysis. JAMA. 2002;288: $728-737$

5. Losch H, Dammann O. Impact of motor skills on cognitive test results in very-low-birthweight children. J Child Neurol. 2004; 19:318-322

6. Stuss DT, Alexander MP. Executive functions and the frontal lobes: a conceptual view. Psychol Res. 2000;63:289-298

7. Costeloe K, Hennessy E, Gibson AT, Marlow N, Wilkinson AR. The EPICure study: outcomes to discharge from hospital for infants born at the threshold of viability. Pediatrics. 2000;106: 659-671

8. Kaufman A, Kaufman N. Kaufman Assessment Battery for Children. Circle Pines, MN: Pearson; 1983

9. Wolke D, Rizzo P, Woods S. Persistent infant crying and hyperactivity problems in middle childhood. Pediatrics. 2002;109: 1054-1060

10. Henderson SE, Sudgen DA. The Movement Assessment Battery for Children. New York, NY: Brace and Jovanovich, Psychological Corporation; 1992

11. Korkman M, Kirk U, Kemp S. Manual for the NEPSY: A Developmental Neuropsychological Assessment. San Antonio, TX: Psychological Testing Corporation, Harcourt Brace Jovanovich, Inc; 1998

12. Fog E, Fog M. Cerebral inhibition examined by associated movements. In: Bax M, MacKeith R, eds. Minimal Cerebral Dysfunction. London, United Kingdom: National Spastics Society; 1963:52-57
13. Evans P, Alberman E, Johnson A, Mutch L. Standardisation of recording and reporting cerebral palsy. Dev Med Child Neurol. 1987;29:272

14. Shonkoff JP, Hauser-Cram P. Early intervention for disabled infants and their families: a quantitative analysis. Pediatrics. 1987;80:650-658

15. Schneider W, Wolke D, Schlagmuller M, Meyer R. Pathways to school achievement in very preterm and full term children. Eur J Psychol Educ. 2004;19:385-406

16. Hertzig ME. Neurological "soft" signs in low-birthweight children. Dev Med Child Neurol. 1981;23:778-791

17. Marlow N, Roberts BL, Cooke RW. Motor skills in extremely low birthweight children at the age of 6 years. Arch Dis Child. 1989;64:839-847

18. Powls A, Botting N, Cooke RW, Marlow N. Handedness in very-low-birthweight (VLBW) children at 12 years of age: relation to perinatal and outcome variables. Dev Med Child Neurol. 1996;38:594-602

19. Marlow N, Roberts BL, Cooke RW. Laterality and prematurity. Arch Dis Child. 1989;64:1713-1716

20. Saigal S, Rosenbaum P, Szatmari P, Hoult L. Non-right handedness among ELBW and term children at eight years in relation to cognitive function and school performance. Dev Med Child Neurol. 1992;34:425-433

21. Ross G, Lipper EG, Auld PA. Hand preference of four-year-old children: its relationship to premature birth and neurodevelopmental outcome. Dev Med Child Neurol. 1987;29:615-262

22. Ross G, Lipper E, Auld PA. Hand preference, prematurity and developmental outcome at school age. Neuropsychologia. 1992; 30:483-494

23. Wood NS, Costeloe K, Gibson AT, Hennessy EM, Marlow N, Wilkinson AR. The EPICure Study: growth and associated problems in children born at 25 weeks of gestational age or less. Arch Dis Child Fetal Neonatal Ed. 2003;88:F492-F500

24. Inder TE, Warfield SK, Wang H, Huppi PS, Volpe JJ. Abnormal cerebral structure is present at term in premature infants. Pediatrics. 2005; 115:286-294

25. Kapellou O, Counsell SJ, Kennea N, et al. Abnormal cortical development after premature birth shown by altered allometric scaling of brain growth. PLoS Med. 2006;3:e265

26. Anderson PJ, Doyle LW. Executive functioning in school-aged children who were born very preterm or with extremely low birth weight in the 1990s. Pediatrics. 2004;114:50-57

27. Bohm B, Smedler AC, Forssberg H. Impulse control, working memory and other executive functions in preterm children when starting school. Acta Paediatr. 2004;93:1363-1371

28. Bohm B, Katz-Salamon M, Institute K, Smedler AC, Lagercrantz H, Forssberg H. Developmental risks and protective factors for influencing cognitive outcome at $51 / 2$ years of age in very-low-birthweight children. Dev Med Child Neurol. 2002;44: $508-516$

29. Vicari S, Caravale B, Carlesimo GA, Casadei AM, Allemand F. Spatial working memory deficits in children at ages 3-4 who were low birth weight, preterm infants. Neuropsychology. 2004; 18:673-678

30. Harvey JM, O'Callaghan MJ, Mohay H. Executive function of children with extremely low birthweight: a case control study. Dev Med Child Neurol. 1999;41:292-297

31. Marlow N. Neurocognitive outcome after very preterm birth. Arch Dis Child Fetal Neonatal Ed. 2004;89:F224-F218

32. Hille ET, den Ouden AL, Saigal S, et al. Behavioural problems in children who weigh $1000 \mathrm{~g}$ or less at birth in four countries. Lancet. 2001;357:1641-1643 
APPENDIX 1 NEPSY: Performance on Visual Attention Task for EP and Comparison Groups

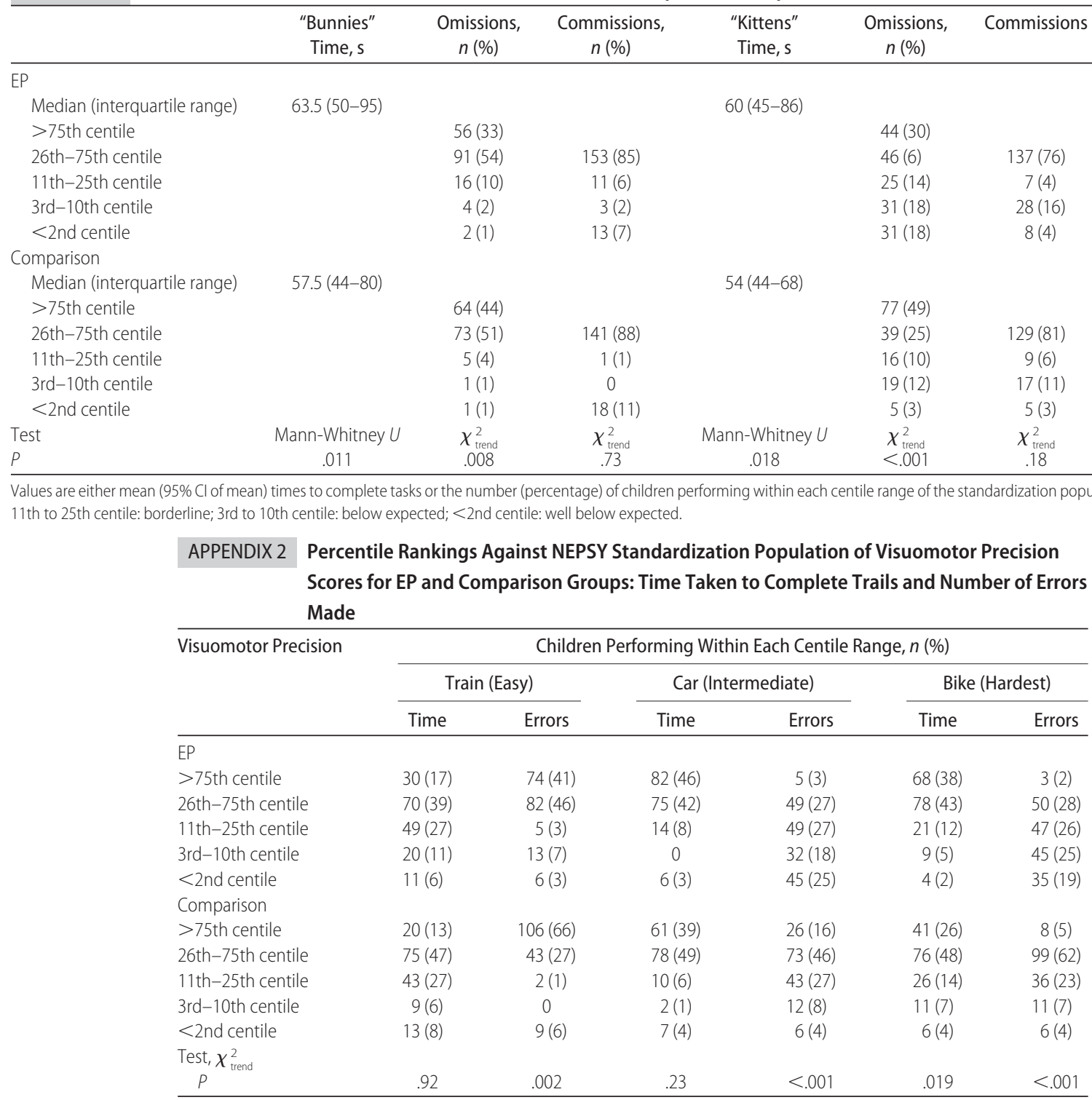

APPENDIX 3 NEPSY Supplemental Items

\begin{tabular}{cccccc}
\multicolumn{5}{c}{ Children Performing Within Each Centile Range of the Standardization Population, $n$ (\%) } \\
$\begin{array}{l}\text { Route Finding } \begin{array}{c}\text { Knock and Tap } \\
\text { (VS) }\end{array} \\
\text { (AE) }\end{array}$ & $\begin{array}{c}\text { Finger Discrimination } \\
\text { (SM) }\end{array}$ & Imitating Hand Postures (SM) & $\begin{array}{c}\text { Manual Motor } \\
\text { Sequences (SM) }\end{array}$
\end{tabular}

$\mathrm{EP}$, median (interquartile range)

\begin{tabular}{|c|c|c|c|c|c|c|c|}
\hline$>75$ th centile & $13(7)$ & $24(14)$ & $7(4)$ & $12(7)$ & $5(3)$ & $5(3)$ & $3(2)$ \\
\hline 26th-75th centile & $70(39)$ & $67(38)$ & $62(35)$ & $45(26)$ & $56(31)$ & $58(33)$ & 49 (27) \\
\hline 11th-25th centile & $61(34)$ & $49(28)$ & $34(19)$ & $39(22)$ & $49(27)$ & $46(26)$ & $56(31)$ \\
\hline $3 \mathrm{rd}-10$ th centile & $32(18)$ & $23(13)$ & $38(22)$ & $53(30)$ & $51(29)$ & $50(28)$ & $58(32)$ \\
\hline$<2$ nd centile & $3(2)$ & $12(7)$ & $36(20)$ & $26(15)$ & $18(10)$ & $18(10)$ & $13(7)$ \\
\hline
\end{tabular}

Comparison, median

(interquartile range)$$
>75 \text { th centile }
$$

26th-75th centile

11th-25th centile

3 rd-10th centile

$<2$ nd centile

$P\left(\chi_{\text {trend }}^{2}\right)$

$\begin{array}{ccc}13(7) & 24(14) & 7(4) \\ 70(39) & 67(38) & 62(35) \\ 61(34) & 49(28) & 34(19) \\ 32(18) & 23(13) & 38(22) \\ 3(2) & 12(7) & 36(20) \\ & & \\ & & \\ 50(31) & 36(23) & 19(12) \\ 67(42) & 101(64) & 93(59) \\ 26(16) & 16(10) & 32(20) \\ 15(9) & 5(3) & 10(6) \\ 1(1) & 1(1) & 5(3) \\ <.001 & <.001 & <.001\end{array}$

$32(20)$

$21(13)$

$71(45)$

$27(17 \%)$

$84(53)$

$25(16)$

$29(18) \quad 23(14)$

$7(5)$

$<.001$

$<.001$

$27(17)$
$87(54)$
$31(19)$
$13(8)$
$2(1)$
$<001$ 


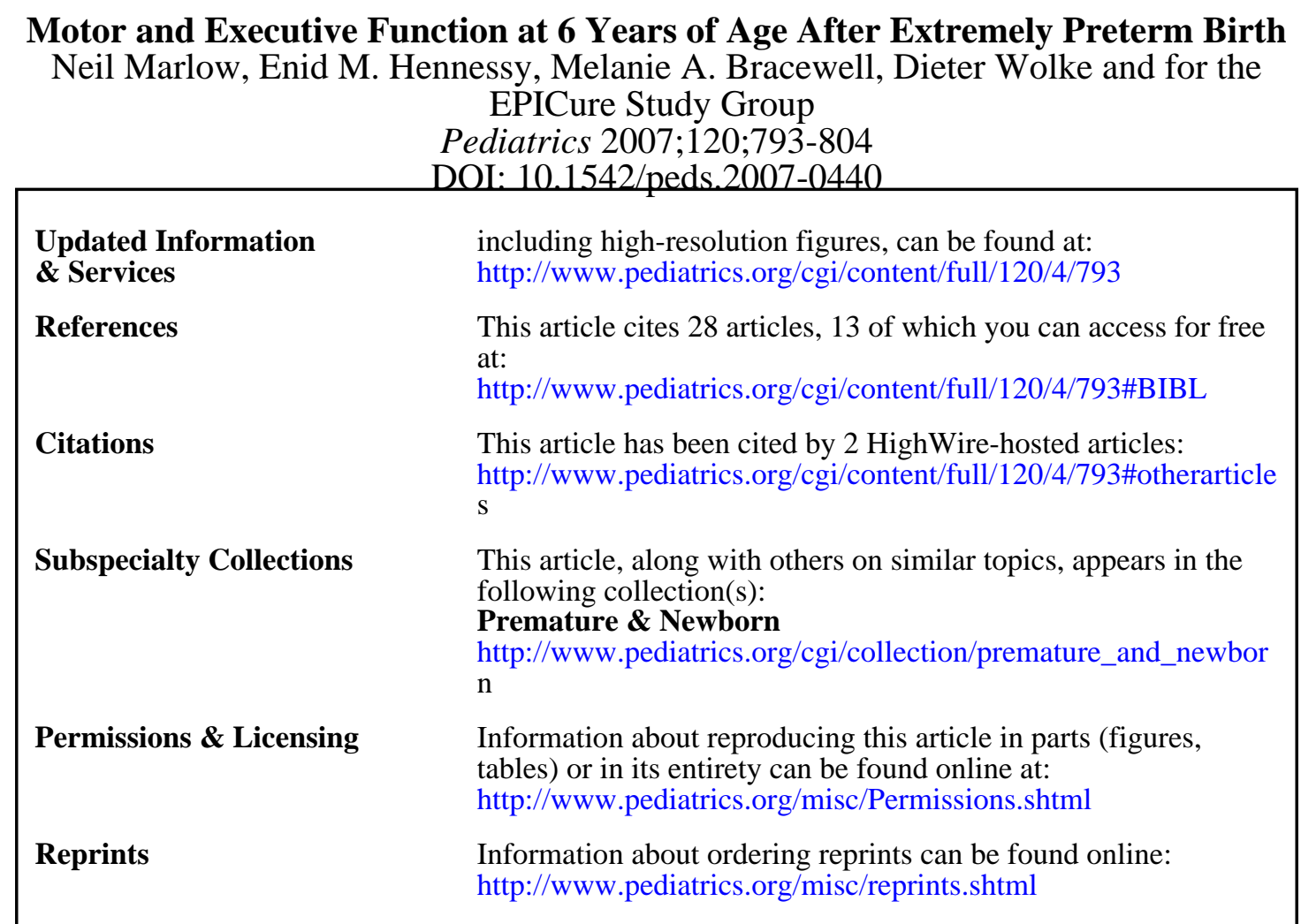

\section{American Academy of Pediatrics}

